Supplement of Nat. Hazards Earth Syst. Sci., 20, 1247-1265, 2020

https://doi.org/10.5194/nhess-20-1247-2020-supplement

(c) Author(s) 2020. This work is distributed under

the Creative Commons Attribution 4.0 License.

(c) (1)

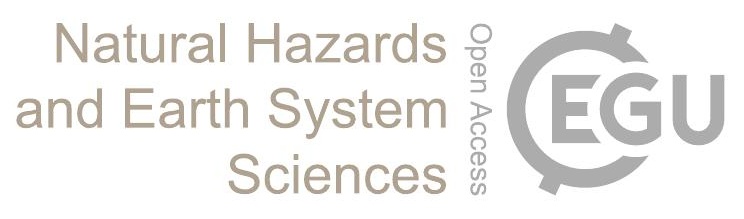

Supplement of

\title{
Erosion after an extreme storm event in an arid fluvial system of the southern Atacama Desert: an assessment of the magnitude, return time, and conditioning factors of erosion and debris flow generation
}

Germán Aguilar et al.

Correspondence to: Germán Aguilar (german.aguilar@amtc.cl)

The copyright of individual parts of the supplement might differ from the CC BY 4.0 License. 


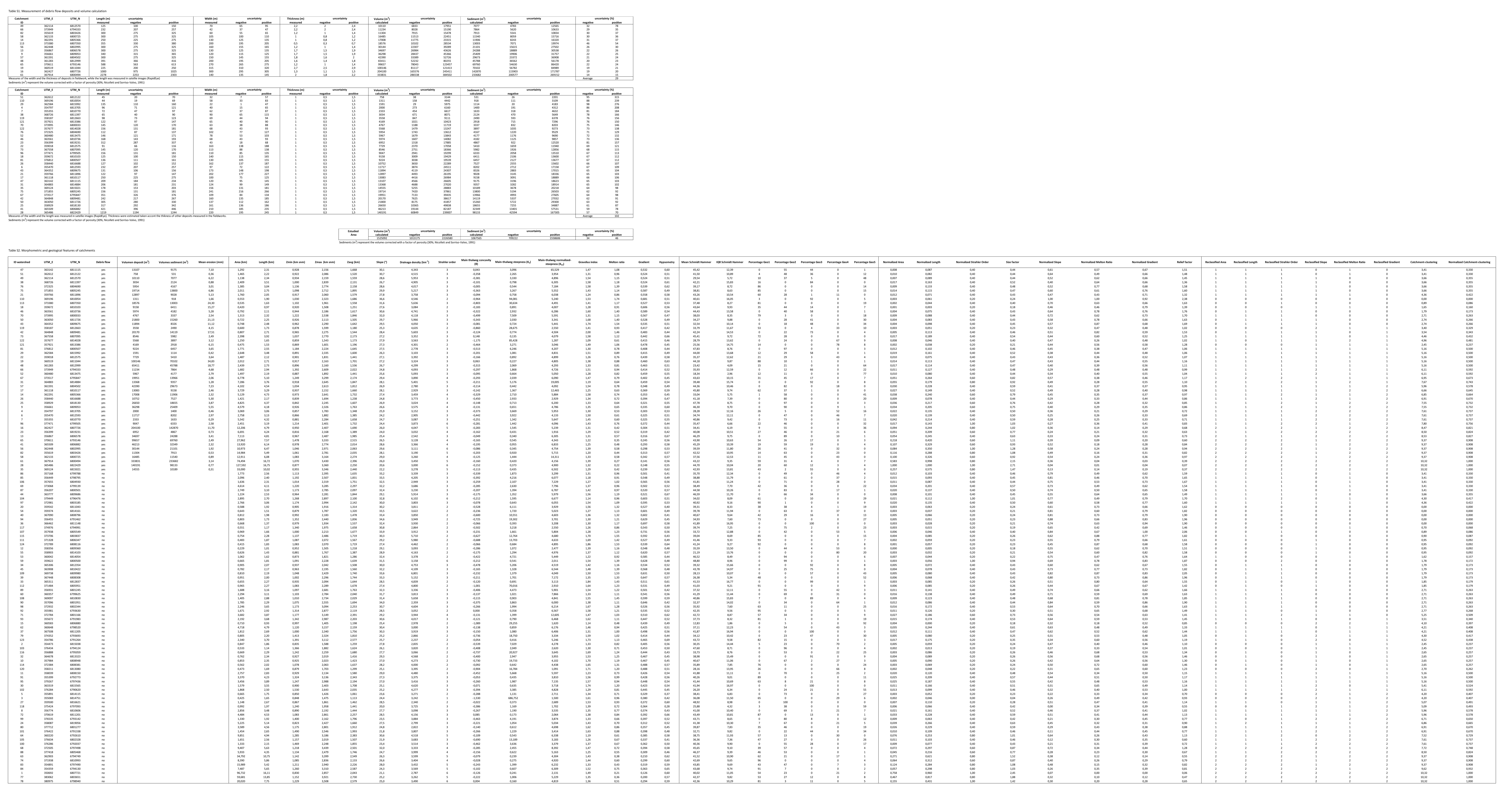

